\title{
Leitura, instrumento formativo: \\ o relato de uma experiência
}

\section{Reading, training instrument:}

the report of an experience

\section{Lectura, instrumento de formación \\ relato de una experiencia}

\author{
MARIANA LUZIA CORRÊA THESING* \\ Universidade Federal de Santa Maria, Santa Maria- RS, Brasil
}

RESUMO: Este texto apresenta o relato e a análise da experiência docente realizada em um curso de formação de professores, nas disciplinas Didática da Linguagem I e Supervisão de Estágio. Como resultados, defende-se queé fundamental que, em cursos de formação de professores, sejam desenvolvidos estudos sobre a relação entre a teoria e a prática pedagógicas e que a atividade de leitura seja entendida como um instrumento formativo. Conclui-se que a indissociabilidade entre teoria e prática pedagógicas é uma exigência fundamental para a formação de professores, numa perspectiva omnilateral, comprometida com uma educação crítica e emancipatória.

Palavras-chave: Formação de professores. Relação teoria-prática. Leitura.

\begin{abstract}
This paper presents the report and analysis of the teaching experience carried out in a teacher training course, in the disciplines of Language I and Internship Supervision. As a result, it is argued that it is essential that, in teacher training courses, studies are developed on the relationship between pedagogical theory and practice and that reading activity is understood as a formative instrument. It is concluded that the inseparability between pedagogical theory and practice is a
\end{abstract}

* É doutoranda do Programa de Pós-Graduação em Educação da Universidade Federal de Santa Maria e mestre em Educação pelo Programa de Pós-Graduação em Educação pela Pontifícia Universidade Católica do Rio Grande do Sul. Atua como professora no Colégio de Aplicação do Centro de Educação da Universidade Federal de Santa Catarina. E-mail: <marluzcor@gmail.com>. 
fundamental requirement for teacher education, in na omnilateral perspective, committed to a critical and emancipation.

Keywords: Teacher training. Theory-practice relation. Reading.

RESUMEN: Este texto presenta el relato y el análisis de la experiencia docente realizada en un curso de formación docente, en las asignaturas Didáctica del Lenguaje I y Supervisión de Prácticas/Pasantía. Como resultado, se defiende que es esencial que em los cursos de formación docente se desarrollen estudios sobre la relación entre la teoria y la práctica pedagógica y que la actividad lectora se entienda como un instrumento formativo. Se concluye que la inseparabilidad entre la teoría y la práctica pedagógica es un requisito fundamental para la formación de profesores, en una perspectiva omnilateral, comprometida con una educación crítica y emancipadora.

Palabras clave: Formación de profesores. Relación teoría-práctica. Lectura.

\section{Introdução}

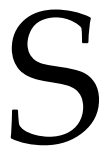

er professor exige responsabilidade pelos caminhos metodológicos escolhidos. Isso porque nenhum caminho, nenhuma escolha, é neutro quando se trata sobre o ato pedagógico. O ato pedagógico é um ato político (FREIRE, 1991) e está sempre embasado em determinada concepção de homem, de sociedade, de educação. Por isso, a tarefa docente, mesmo que tacitamente, está compromissada com a manutenção ou com a transformação das condições sócio-históricas existentes.

A partir da compreensão de que todos podem aprender uns com os outros, e que o professor não é o único quem ensina na tarefa educativa, este texto é escrito a partir da compreensão de que professor e estudantes são "capazes de juntos tornarem-se partícipes dos processos de educação escolar, numa perspectiva que os liberta da condição de oprimidos para a consciência de suas possibilidades como sujeitos transformadores de suas vidas e realidades" (CORRÊA, 2013, p. 18).

Consciente dessa condição, este texto apresenta um relato de experiência sobre o ser professora em um curso de magistério, na modalidade de ensino médio/curso normal, que visa à formação de professores habilitados ao trabalho pedagógico em turmas da educação infantil e dos anos iniciais do ensino fundamental. Com essa proposição, este texto apresenta a contextualização da prática desenvolvida e elementos referentes a cada uma das etapas do trabalho desenvolvido, em duas disciplinas em um curso de 
magistério, ofertado em uma instituição escolar pública, numa cidade da fronteira-oeste do Rio Grande do Sul/Brasil.

As disciplinas intitulavam-se Didática da Linguagem I e Supervisão de Estágio, desenvolvidas durante o segundo semestre de 2015, com estudantes de um curso de magistério, em nível médio. Cada disciplina foi ofertada para turmas diferenciadas, de diferentes períodos do curso, este que era composto por quatro semestres. A disciplina Didática da Linguagem I é uma disciplina pertencente ao primeiro semestre do curso e a disciplina Supervisão de Estágio era ofertada no último semestre do curso, período em que as estudantes estavam envolvidas com as atividades de estágio curricular supervisionado.

Este relato tem a pretensão de afirmar a importância do trabalho acerca da indissociabilidade entre a teoria e prática pedagógicas, mesmo em um curso de curta duração como este em que a experiência foi desenvolvida. A atividade de leitura como instrumento de construção do conhecimento pedagógico e como elemento formativo foi a base de todo o processo pedagógico, em ambas as disciplinas.

O trabalho em um curso de formação de professores exigiu reflexões sobre o processo formativo, tendo em vista os conhecimentos base para a formação e para a atuação desses profissionais na escola. O trabalho desenvolvido em classes de alfabetização nos anos iniciais escolares fora fundamental para o planejamento e para o desenvolvimento do trabalho como professora formadora de novos professores. A partir da experiência docente em turmas dos anos iniciais escolares, da pesquisa acadêmica sobre temas relacionados à docência, o trabalho pedagógico desenvolvido nas disciplinas Didática da Linguagem I e Estágio Supervisionado teve como objetivo a formação de professores leitores, críticos e compromissados com uma educação crítica e emancipatória.

\section{Contextualizando a prática pedagógica}

A escola, contexto do trabalho educativo, é uma instituição pública, mantida pelo Governo Estadual, situada em uma cidade da fronteira-oeste do Rio Grande do Sul/Brasil. A instituição escolar, que conta com mais de 100 professores e cerca de 2.000 estudantes matriculados em diferentes níveis de ensino, tem mais de 80 anos de história e é uma instituição respeitada na cidade onde se situa. Por ser uma "escola de aplicação", oferta, além do curso de magistério/nível médio, matrículas na educação infantil, no ensino fundamental (anos iniciais aos finais), no ensino médio e na EJA (educação de jovens e adultos), esta ofertada no período noturno.

O curso de magistério/curso normal ofertado pela escola tinha duas modalidades: um curso de magistério, em nível de ensino médio, com duração de três anos; e o outro, pós-médio, com duração de dois anos. Na primeira modalidade do curso, os estudantes 
cursistas tinham, além das disciplinas obrigatórias, o período destinado a dois estágios: um inicial, com quinze dias de duração, antecedidos por observações sistemáticas do trabalho dos professores regentes das turmas, e o último com duração de cinco meses. em que os estudantes formandos poderiam optar por fazê-lo em turmas de educação infantil ou em turmas dos anos iniciais do ensino fundamental.

Outra modalidade do curso configurava-se como um curso pós-médio, em que os estudantes se formavam em um período de dois anos. Nesse percurso, no decorrer dos primeiros dezoito meses, estava prevista a oferta de disciplinas obrigatórias e, no último semestre de curso, a prática de estágio obrigatório. Essa última modalidade de curso recebia matrículas de pessoas que já haviam concluído o ensino médio e que manifestavam o desejo pela carreira docente. O perfil das pessoas dessa modalidade de curso variava significativamente: jovens recém-formados nos cursos de ensino médio e pessoas com diferentes idades interessadas na continuidade dos estudos. Nessa experiência, minha atividade como professora se desenvolveu no curso de magistério pós-ensino médio, em duas disciplinas: Didática da Linguagem I e Supervisão de Estágio.

Na disciplina de Didática da Linguagem I, ofertada no primeiro semestre do curso, a proposta de trabalho versava sobre os processos de alfabetização e de letramento. As aulas eram semanais, com carga horária de duas horas/aula. A turma era constituída por 22 estudantes, todas mulheres. A turma tinha um perfil diversificado. Eram pessoas de diferentes idades, porém todas interessadas em se tornar professoras de crianças.

A disciplina Supervisão de Estágio, por sua vez, configurava-se como um espaço de orientação das estudantes do curso que estavam desenvolvendo a prática do estágio obrigatório final. A disciplina envolvia visitas às escolas, realizadas semanalmente.

\section{Didática da linguagem I: o desafio da atividade leitora como instrumento formativo}

\footnotetext{
As escolhas pedagógicas são embasadas em determinadas concepções de homem, de sociedade e de educação. Nessa perspectiva, Luckesi (2014, p. 46) afirma que "um educador, que se preocupe com que a sua prática educacional esteja voltada para a transformação, não poderá agir inconsciente e irrefletidamente [...]", pois considera que a atividade docente não é uma ação mecânica, apolítica e neutra.
}

O planejamento do trabalho pedagógico, sua execução e avaliação dos processos de ensino e de aprendizagem são ações que compõem o ato pedagógico (LUCKESI, 2014), que, por sua vez, tem como principal objetivo a democratização do conhecimento e a transformação social. Desta maneira, o ato pedagógico não é um ato neutro, sem relação com as teorias de educação e com diferenciadas perspectivas epistemológicas.

Para Cortella (2017), a forma como entendemos o processo de construção do conhecimento, que "nem sempre é consciente e reflexiva” (p.49) “[...] tem desdobramentos 
políticos e epistemológicos profundos nas nossas práticas e por isso é preciso iluminar sua gênese de modo a permitir maior consistência e consciência em nossas ações educativas" (CORTELLA, 2017, p. 49-50). Para o autor (2017, p. 114), o professor é um profissional "que tem um papel político/pedagógico" e sua atividade "não é neutra e nem absolutamente circunscrita". Para ele (2017), longe de um “otimismo pedagógico" e de um "pessimismo ingênuo", a educação escolar pode ser um espaço efetivo de inovação na prática pedagógica, tendo em vista a democratização do conhecimento.

A relação entre teoria e prática na formação de professores exige a discussão epistemológica sobre o processo de formação docente, a partir de alguns questionamentos fundantes: quem é o professor a ser formado? A partir de que conhecimentos? A partir de que bases epistemológicas? Nessa perspectiva, Freire (2011), defende que um dos saberes necessários à prática do professor é o reconhecimento de que o ato de ensinar é um ato político e que a educação, em sua essência, é ideológica. Para Freire (2011, p.141-142),

Saber igualmente fundamental à prática educativa do professor ou da professora é o que diz respeito à força, às vezes maior do que pensamos, da ideologia. É o que nos adverte de suas manhas, das armadilhas em que nos faz cair. É que a ideologia tem a ver diretamente com a ocultação da verdade dos fatos, com o uso da linguagem para penumbrar ou opacizar a realidade ao mesmo tempo em nos torna míopes.

Diante do caráter político do ato pedagógico, planejar o trabalho a ser desenvolvido na disciplina Didática da Linguagem I, na modalidade pós-médio, provocou questionamentos: quais seriam os saberes necessários a serem trabalhados nesse percurso formativo? Como organizar o tempo do trabalho tendo em vista o número de hora/aulas disponíveis para o trabalho com as estudantes? Como desenvolver o trabalho em um curso de formação de professores, estimulando a atividade leitora e escritora, com estudantes cursistas no primeiro ano do magistério, considerando que muitas delas há muito tempo estavam afastadas dos estudos acadêmicos escolares? Quais os conhecimentos que deveriam ser objeto de estudo e debate nas aulas e a partir de quais materiais e meios didáticos? Como avaliar a aprendizagem das estudantes de forma inclusiva e processual?

A Didática da Linguagem I é uma disciplina que se voltava ao estudo da metodologia de ensino dos processos de alfabetização inicial e era seguida de uma segunda disciplina: Didática da Linguagem II, em que a proposta estaria voltada a dar maior ênfase ao trabalho com a língua materna e a atividades práticas a serem propostas na educação escolar. Nessa disciplina, vinte estudantes estavam matriculadas. Nessa lógica, para dar conta dos conhecimentos relevantes a serem trabalhados, foi necessária a organização de um mapa de relevância de conhecimentos (MACHADO, 2011), que foi utilizado como um instrumento orientador do caminho a ser percorrido na disciplina. Isso porque, apesar do pouco tempo que tínhamos em cada aula, havia o compromisso de trabalhar para além das discussões sobre o que fazer, mas também, principalmente, sobre os porquês das escolhas metodológicas. 
Devido ao tempo de aula previsto para cada encontro è dificuldade das estudantes por estarem, em sua maioria, há bastante tempo distanciadas das atividades escolares, tínhamos um desafio: aprender juntas a pensar sobre a docência - sobre a atividade alfabetizadora e sobre a docência em um curso de formação de professores, para além do saber fazer.

Cada uma das aulas teve como fio condutor o trabalho com as teorias relacionadas à alfabetização inicial, levando em consideração a legislação vigente e as pesquisas recentes na área. Cada encontro exigia uma leitura prévia de pequenos textos sobre o tema da aula, feita pelas estudantes e a escrita individual a partir das leituras propostas. Os textos trabalhados além de terem sido disponibilizados materialmente às estudantes, em uma pasta da disciplina, foram enviados também via e-mails, porém de forma gradual, tendo em vista que somente a partir da disciplina e da proposição dessa dinâmica, a maioria das estudantes criou contas de correio eletrônico.

Os textos, redigidos pelas estudantes, deveriam ser apresentados a cada aula, de forma individual. A escolha metodológica pela leitura e por escritas individuais é justificada pelo anseio de que cada uma das estudantes ensaiasse suas compreensões a partir das leituras em pequenos textos. Isso porque é entendido que a prática da leitura, do estudo e da escrita em um curso de formação de professores são atividades basilares para a formação de profissionais comprometidos com a democratização do conhecimento.

No intuito de realizar uma avaliação de caráter processual, além das atividades relacionadas à leitura e à escrita, a disciplina exigiu das estudantes atividades avaliativas: entrevista com professores atuantes na educação infantil e/ou nos anos iniciais do ensino fundamental sobre o trabalho com a língua materna na escola; o estudo e a organização de uma apresentação, em forma de seminário, sobre um tema relacionado à disciplina a partir da prática da pesquisa e de estudo de textos específicos sobre o tema; e a elaboração de um jogo ou material didático, com respectivo texto instrucional, que pudesse ser utilizado nas práticas de ensino da linguagem na escola e que, posteriormente, pudesse constituir-se também como material didático para as colegas.

A avaliação, considerada por Luckesi (2014) como uma tarefa inclusiva, contextual e dinâmica, deve ser realizada a partir de diferentes instrumentos e em diferentes momentos do trabalho educativo. Para o autor, a avaliação não é uma atividade neutra, e tampouco uma atividade fim, podendo estar associada à democratização do conhecimento ou à domesticação dos sujeitos.

A turma de estudantes, inicialmente, teve dificuldades em compreender a proposição das diferentes atividades no que se refere à sua formação como professoras. Registra-se que no primeiro conselho de classe da turma, em que os professores se faziam presentes para ouvir as manifestações das estudantes e também relatar elementos pertinentes sobre o trabalho desenvolvido, metade da turma manifestou-se indignada com a prática de leitura proposta pela disciplina Didática da Linguagem I. 
Com uma postura rigorosa e exigente em relação à proposição metodológica inicial, a defesa da atividade de leitura foi mantida na continuidade do curso, apesar da resistência das estudantes. Isso porque se compreende que a atividade de leitura habilita os professores à atividade de reflexão e de busca por novos conhecimentos. Para Ghiggi, Chaves e Silva (2017, p. 128), as atividades de ler e de escrever nos processos formativos de professores podem ser instrumentos para "um constante processo de revisitar a prática e a sua teoria, direcionando o fazer a um inacabado momento de rever-se".

Cabe esclarecer que o rigor, na prática educativa, é entendido nesse texto como um elemento distanciado da rigidez e da coerção, características de práticas docentes autoritárias. Shor \& Freire (2013) argumentam que o rigor está relacionado à busca pelo conhecimento, pela dedicação do sujeito diante do ato de conhecer, de aprender. Para eles, “o rigor é um desejo de saber, uma busca de resposta, um método criativo de aprender. Talvez o rigor seja, também, uma forma de comunicação que provoca o outro a participar, ou inclui o outro numa busca ativa" (FREIRE \& SHOR, 2013, p. 14).

É importante questionar sobre a formação docente isenta de leituras e estudo aprofundado das bases teóricas que fundamentam as práticas pedagógicas. Que saberes são considerados necessários no processo de formação de professores, não passíveis de estudos e leituras prévias? De que forma trabalhar com a formação de professores isentando da atividade de leitura diante da complexidade da formação de professores e dos saberes da docência? Quais os saberes eram prioridades em um curso de formação docente: os referentes ao saber fazer ou àqueles relativos ao saber o porquê fazer?

Ao final do semestre, as estudantes, a partir de suas avaliações sobre a disciplina, escritas de forma não identificada, indicaram mudança em suas formas de compreender a importância da leitura e da escrita em seus processos formativos. Algumas estudantes escreveram:

\footnotetext{
“Obrigada por não desistir da nossa turma e por insistir nas atividades de leitura, agora gosto de ler e estou lendo muitas coisas" (ESTUDANTE PESQUISA).

"Ainda não gosto de ler, mas sei que é importante na profissão que escolhi. Aprendi bastante nas aulas e com as leituras" (ESTUDANTE ÉTICA).

"As leituras valeram a pena [...] Quero fazer Pedagogia e sei que vou ter que ler bastante" (ESTUDANTE DIÁLOGO).
}

O pressuposto de que a teoria educacional nada tem a ver com a prática profissional, por vezes afirmada equivocadamente, é um risco para os processos de formação de professores, que, embasados nessa ideia, correm o risco de sofrer um processo de desintelectualização docente (SHIROMA, 2003). Teoria e prática são elementos interdependentes: a teoria sem a prática configura-se como um texto esvaziado de sentidos e a prática sem a teoria é ação intuitiva e improvisada. Talvez essa seja a justificativa da proposição da metodologia de trabalho adotada: é preciso olhar para a prática do professor, pensando 
em ações que lhe sejam possíveis na escola, sem esquecer dos pressupostos que as justificam como práticas significativas, intencionais e planejadas, tendo em vista o direito à aprendizagem dos estudantes.

\section{A supervisão de estágio": o olhar atencioso e orientador das práticas de estágio}

A visita às escolas de educação infantil e dos anos iniciais do ensino fundamental a fim de observar o planejamento e as práticas das estudantes em atividade de estágio resultou em aprendizagens compartilhadas. Isso porque estamos, como professores, numa relação dialética com os estudantes, sempre ensinando e aprendendo (FREIRE, 2011).

Nesse movimento, a observação da prática das professoras estagiárias e de suas turmas tinha o objetivo de acompanhar o processo formativo de cada uma das professoras em formação, auxiliando-as diante dos diferenciados desafios do trabalho docente. No decorrer do processo, o papel do professor supervisor de estágio teve a intencionalidade de propor estratégias para o trabalho pedagógico, voltado aos processos de ensino e de aprendizagem. Isso porque cada contexto escolar, cada turma e cada uma das estudantes estagiárias exigiu um pensar atencioso sobre a tarefa docente e sobre os desafios cotidianos da profissão professor.

Nesse processo, as experiências anteriores como professora de crianças nos anos iniciais escolares forneceram elementos que auxiliaram nas orientações das estudantes estagiárias em suas práticas docentes. A prática da supervisora de estágio, nesse viés, não se limitava a apenas observar e avaliar, mas também a orientar as estudantes estagiárias para futuros planejamentos relacionados à prática de ensino.

Ao total, eram dez professoras estagiárias. As visitas eram semanais e, para acompanhá-las, a cada duas semanas visitava as mesmas professoras estagiárias. Em sua maioria, eram dedicadas à organização de seus cadernos de planejamento e com suas salas de aula. Destaca-se que a maioria das professoras estagiárias observadas não tinham problemas ao planejar as atividades, prática orientada pelas professoras do curso, mas não orientadas pelas professoras das escolas em que desenvolviam seus estágios: pareciam saber quais atividades pedagógicas propor às crianças, mesmo que algumas dessas atividades não tivessem relação com outras já trabalhadas. Nesses contextos escolares, as professoras regentes das turmas não acompanhavam as professoras estagiárias em classe, mas se mantinham disponíveis sempre que era necessário.

Grande parte das professoras estagiárias apresentava dificuldades em planejar atividades voltadas ao "corpo e ao movimento". Era necessário incentivá-las a planejar atividades externas com as crianças. Tal fenômeno foi também observado em relação à proposição de atividades voltadas à produção textual e à análise linguística: poucas professoras desafiavam os estudantes de suas turmas a escrever e analisar produções textuais. 
As professoras estagiárias também demonstraram ter muita preocupação com o "controle" da turma, manifestando comportamentos demasiadamente controladores, o que pode estar relacionado às dificuldades de desenvolver atividades no pátio das escolas. Nos momentos de visita, a maioria das professoras estagiárias alertavam as crianças sobre o ato de conversar, chamando-as à atenção corriqueiramente. Em algumas visitas, conversei com algumas delas sobre esse interesse em ter o silêncio como elemento permanente em sala, o que na minha compreensão faz-se necessário em momentos de atividades individuais, mas não obrigatório à dinâmica de uma turma aprendente.

O trabalho na disciplina Supervisão de Estágio foi uma experiência interessante, pois proporcionou a reflexão e a intervenção pedagógica em diferenciadas práticas de estágio e contextos educacionais escolares diferenciados. Cada uma das professoras estagiárias, a partir de seus planejamentos e estratégias de ensino, provocou reflexões acerca dos desafios da docência e dos significados de ser professor diante de diferenciados contextos escolares.

\section{As professoras estagiárias}

O professor, envolvido nas atividades na escola, trabalha diretamente com o conhecimento - este que é o principal objetivo da escola, apesar das diferentes funções a ela atribuídas pelas diferentes pedagogias. $\mathrm{O}$ trabalho pedagógico com o conhecimento exige uma tomada de decisão frente aos processos de aprender e ensinar que justifique as escolhas didático-metodológicas do professor. Essa tomada de decisão é entendida como fundamental para o processo de construção do conhecimento e para os processos de aprendizagem e desenvolvimento humanos. Com base nessa premissa, algumas situações vivenciadas nas práticas de estágio são apresentadas a fim de ilustrar as situações vivenciadas pelas estudantes estagiárias, em seus processos de constituição do ser professor. Dentre as dez estudantes estagiárias, três foram selecionadas devido às suas diferenciadas experiências e especificidades, muitas delas comuns a de muitos professores considerados "experientes" na profissão. O anonimato das professoras estagiárias, identificadas com nomes fictícios, é garantido nesse relato.

\section{"Esperança": estudante estagiária}

Esperança foi uma das professoras estagiárias que visitei após ouvir muitos elogios pela Coordenação Pedagógica do Curso, que afirmava: "Vais adorá-la, é uma ótima professora! [...]", "Esta está muito bem, só tem conceitos bons". Contudo, quando fui visitá-la, sua sala de aula era repleta de crianças sentadas uma atrás da outra, em um silêncio admirável, que me chamou a atenção. 
A estudante estagiária, que parecia tensa com a minha presença, escrevia no quadro, durante a tarde, exercícios desarticulados em que pedia: "circulem verbos no passado"; "pinte o masculino", "resolva as continhas". Quando as crianças, silenciosas, terminavam suas cópias, a professora apagava e escrevia no quadro novas lições, de forma ininterrupta.

Durante a observação da aula e após a análise de seu planejamento semanal, foi percebida a inexistência de atividades com textos (leitura, produção e análise linguística), a falta de proposições de problemas matemáticos e também de atividades externas com a turma. Havia poucas atividades referentes às artes plásticas e uma significativa quantidade de "atividades "avulsas", sem articulações entre si.

Após o término da aula, quando questionada sobre seu planejamento e diante da defesa da inclusão de atividades inexistentes em seu planejamento, a professora estagiária, assim justificou: "Comigo, essa história de conversa, de brincadeira no pátio não dá [...] vira uma bagunça" (ESPERANÇA).

Diante desse cenário, é interessante pensar sobre os critérios elencados que definiram a avaliação positiva, dada pela maioria dos professores formadores de um curso, do trabalho pedagógico de uma professora estagiária que propunha atividades inertes [e, talvez, enfadonhas] e que defendia, no início da sua carreira profissional, que "essa história de conversa, de brincadeira no pátio não dá [...]". Sobre o trabalho pedagógico na escola, Thesing (2018) afirma que

\footnotetext{
A proposição de atividades sem uma justificativa pedagógica torna o trabalho do professor uma prática mecânica, intuitiva, voltada a preencher o tempo na escola com exercícios estéreis e enfadonhos. A escola é um espaço onde as crianças devem aprender a ler e a escrever, no qual a leitura e a escrita sejam entendidas como instrumentos políticos, trabalhados a partir de objetivos significativos para os estudantes. (p. 171).
}

Com base nesses pressupostos, questiono: será que uma boa aula é sinônimo de uma aula silenciosa, a partir de atividades voltadas exclusivamente à cópia de exercícios? $\mathrm{O}$ que define um bom planejamento? Quais são as características essenciais ao trabalho pedagógico? Tais questionamentos são motrizes para a reflexão sobre a importância do trabalho com o conhecimento de forma articulada, com base na ludicidade e no significado do ato de aprender para os estudantes das turmas dos anos iniciais escolares.

\section{"Liberdade": estudante estagiária}

Liberdade era uma estudante estagiária que não recebera elogios, como os dados à Esperança, por parte dos professores formadores do Curso. Ao contrário, havia uma séria preocupação em relação ao estágio da estudante. Isso porque consideravam que 
Liberdade não planejava atividades coerentes ao nível da turma, que as atividades que propunha não eram significativas e que não desenvolvia um bom trabalho com as crianças estudantes. Minhas visitas foram frequentes à turma de Liberdade e pude realmente perceber as dificuldades da estudante. Contudo, além desses desafios, como agravante, Liberdade tinha problemas de relacionamento pessoal com a professora regente da turma.

Apesar dessas dificuldades, Liberdade era uma professora estagiária dedicada. Ouvia as orientações com atenção e sempre me recebia com alegria. Colocava-se em escuta para ouvir sugestões e conselhos e os incluía, mesmo com dificuldades, em seus planejamentos futuros. Percebi, nos dias em que a visitava, que era gentil com as crianças e essas a adoravam e respeitavam.

Por vezes, Liberdade foi aconselhada pelos diferentes professores do curso que a visitavam, a procurar o Curso durante seu estágio a fim de conversar com os professores formadores e com a Coordenação Pedagógica, a fim de relatar seus desafios na atividade de estágio. Liberdade era uma estudante que já havia desistido do curso em outra ocasião, por problemas pessoais, e que havia sido autorizada a iniciar a prática de estágio diante do compromisso em dedicar-se ao estágio. Contudo, era nítida sua dificuldade em realizar planejamentos e em desenvolvê-los no dia a dia escolar, acarretando, por vezes, prejuízos de aprendizagem à turma de estudantes envolvida.

\section{"Práxis": estudante estagiária}

Práxis era uma professora estagiária bastante competente em realizar planejamentos. Mantinha seu caderno organizado e era bastante criativa. As atividades eram inter-relacionadas, adequadas ao ano escolar e significativas para o grupo de crianças com o qual trabalhava. Sua turma era composta por 15 crianças, que tinham entre seis e sete anos. Porém, Práxis manifestava dificuldades em gerenciar as condutas das crianças, nem sempre gentis umas com as outras e em relação a ela como professora da turma. Práxis, durante todo o seu percurso como professora estagiária, não havia conseguido construir uma relação de autoridade com a turma.

Em diferentes visitas, mesmo com orientações do que poderia experimentar diante de situações conflituosas ou para envolver os estudantes com comportamentos indisciplinares/resistentes, Práxis enfrentava desafios para ser ouvida, para organizar a turma e para conter agressões entre as crianças. Seu trabalho como professora diante da turma, apesar de apresentar boas propostas em seus planejamentos, não era desenvolvido como seu planejamento previa, desafio que pode ser comum também para professores experientes.

Em algumas situações, quando a turma estava bastante agitada, a professora regente da turma de Práxis conversava com as crianças para que elas demonstrassem 
um comportamento mais ouvinte e atencioso, pedido que nem sempre era atendido pelas crianças. O papel da professora regente da turma era bastante importante nessas situações, pois dava à Práxis segurança para desenvolver suas propostas e lhe dava elementos teórico-práticos para pensar sobre seu próprio processo de formação.

As crianças da turma, apesar de terem pouca idade e de serem poucas no espaço da sala de aula, mantinham comportamentos resistentes às falas da professora regente e também às de Práxis. Diante de tais situações, a cada final de aula, conversava com Práxis sobre as situações vivenciadas e sobre posturas possíveis diante delas. As orientações procuravam fortalecê-la, defendendo a ideia de que ela poderia ter uma postura mais confiante e decidida, pois em algumas situações, demonstrava indecisão e fragilidade diante dos argumentos das crianças. O termo "confiante" não tem relação com práticas autoritárias ou coercitivas. Ser mais confiante na atividade docente está relacionado com a capacidade docente de defender suas escolhas metodológicas a partir de seus pressupostos teóricos e políticos. Eis a necessidade do estudo de teorias pedagógicas que embasem a prática profissional, como instrumentos para o trabalho no cotidiano da escola. A compreensão da relação indissociável entre a teoria e a prática, que muitas vezes é negada pela defesa da primazia do pragmatismo em educação, é a base da formação docente para que os professores sejam capazes de escolher suas metodologias didáticas, que estão fundadas em escolhas epistêmicas.

\section{Considerações finais}

O professor não é o único a ensinar na tarefa educativa: estudantes e professores podem aprender juntos, cotidianamente, numa relação horizontal, a partir do diálogo e da troca de saberes. Contudo, é o professor o responsável pelo planejamento, pelo desenvolvimento e pela avaliação de seu trabalho em busca da construção do conhecimento. Por isso, a importância dos processos formativos de professores fundada em currículos cujos pressupostos pedagógicos sejam base para a prática pedagógica.

A proposição da leitura como uma atividade regular da disciplina “Didática da Linguagem I", bem como o exercício da escrita como instrumento formativo foram exigências da disciplina com intencionalidade formadora. Defende-se que a leitura e a escrita podem contribuir para a formação de novos professores que, leitores e escritores, podem criar novas histórias pessoais e profissionais. Um professor de um curso formador de professores, com uma postura dialógica e rigorosa, precisa convidar os estudantes à prática do estudo e da leitura para que compreendam tais atividades como instrumentos de acesso e de democratização do conhecimento.

Muito mais do que saber fazer cartazes coloridos, é preciso que esses professores saibam como seus alunos aprendem, para então traçar planos de trabalho coerentes com 
seus processos de aprender e de desenvolver. É preciso que os novos professores saibam que avaliar não é aplicar testes, mas considerar os processos de aprendizagem dos estudantes a partir de suas histórias e percursos, com diferentes instrumentos e em tempos diversos do processo pedagógico.

O curso de formação de professores deve se tornar um espaço que convide os estudantes a se dedicarem ao estudo e ao aprofundamento teórico, independentemente da sua duração ou natureza. Pois os estudantes egressos serão professores da educação básica, que almejamos mais democrática e voltada à construção do conhecimento. É preciso, sem desconsiderar a importância dos saberes da prática, formar professores como agentes conscientes das condições históricas da profissão docente, comprometidos com uma educação "para além do capital" (MÉSZAROS, 2008).

Recebido: 04/02/2019 e Aprovado: 21/05/2019

\section{Notas}

1 A leitura não era considerada uma prática habitual/comum no cotidiano das estudantes matriculadas nas disciplinas trabalhadas, exigência que causou ora estranhamento e indignação, ora admiração e reconhecimento por parte das estudantes durante o processo pedagógico.

2 O uso do gênero feminino será utilizado neste texto tendo em vista que a turma de estudantes era composta somente por estudantes mulheres.

3 As visitas eram feitas por alguns professores formadores do Curso, que as faziam de forma alternada. Cada professor deveria visitar as estudantes estagiárias, na frequência de duas semanas seguidas. Após duas semanas subsequentes, era feito um reajuste nas visitas para que todos os professores pudessem visitar a todas as estudantes estagiárias.

4 Ao total tivemos 17 encontros, com carga horária de $2 \mathrm{~h} / \mathrm{a}$ semanais. $\mathrm{O}$ trabalho com as estudantes ocorreu no segundo semestre do ano de 2015, iniciado no dia 13 de agosto e findado no dia 10 de dezembro. Devido às aulas terem uma frequência semanal, com carga horária de $2 \mathrm{~h} / \mathrm{a}$, considerava o tempo como um elemento restrito diante do significativo conjunto de conhecimentos referidos à disciplina.

5 Muitas estudantes da turma não tinham contas de correio eletrônico. A disponibilização dos materiais de forma digital incentivou-as a criarem contas de $e$-mails.

6 A partir da compilação desse material, elaborou-se um arquivo único que foi disponibilizado à turma para que todas as estudantes tivessem acesso às propostas de jogos e materiais didáticos criados pelas colegas da turma.

7 Os nomes dados às estudantes nesse texto são fictícios para preservar suas identidades. Os nomes escolhidos foram embasados na obra Pedagogia da Autonomia: saberes necessários à prática docente, de Paulo Freire (2011).

8 Para cada visita, uma ficha de avaliação deveria ser preenchida, em que o planejamento e a prática de ensino eram avaliados a partir dos seguintes itens: "Ótimo", "Muito Bom", "Bom", "Regular" e "Insuficiente". Além desses indicadores, comentários, recomendações e orientações sobre os itens avaliados poderiam ser registrados. 


\section{Referências}

CORRÊA, Mariana Luzia. Disciplinamento escolar: suas relações com a autoridade docente e com a autonomia dos estudantes em um primeiro ano do Ensino Fundamental. 2013. Dissertação (Mestrado em Educação) - Faculdade de Educação, Pontifícia Universidade Católica do Rio Grande do Sul, Porto Alegre, 2013.

CORTELLA, Mário Sérgio. A escola e o conhecimento: fundamentos epistemológicos e políticos. São Paulo: Cortez, 2017.

FREIRE, Paulo. A educação é um ato político. Cadernos de Ciência, Brasília, n. 24, p. 21-22, 1991.

2011.

Pedagogia da Autonomia: saberes necessários à prática educativa. 43ํㅡㄹ ed. São Paulo: Paz e Terra,

GHIGGI, Gomercindo; CHAVES, Priscilla Monteiro; SILVA, Rogéria Novo da. A formação de leitores assumida como proposta pedagógica: das contradições às congruências. Revista Leitura: Teoria e Prática. Campinas, v. 35, n. 69, pp. 115-130, 2017.

LUCKESI, Cipriano. Avaliação da aprendizagem escolar: estudos e proposições. 22ª ed. São Paulo: Cortez, 2014.

MACHADO, Nilson José. Epistemologia e didática: as concepções de conhecimento e inteligência e a prática docente. $7^{\mathfrak{a}}$ ed. São Paulo: Cortez, 2011.

MÉSZAROS, István. A educação para além do capital. 2ª̣ ed. São Paulo: Boitempo, 2008.

SHIROMA, Eneida Oto. O eufemismo da profissionalização. In: MORAES, Maria Célia Marcondes de (Org) Iluminismo às avessas: produção do conhecimento e políticas de formação de professores. Rio de Janeiro: DP\&A, 2003. p. 61-79.

SHOR, Ira; FREIRE, Paulo. Medo e ousadia: o cotidiano do professor. $1^{\underline{a}}$ ed. Rio de Janeiro: Paz e Terra, 2013.

THESING, Mariana Luzia Corrêa. Ler e escrever na escola: um relato de experiência. Revista Retratos da Escola. CNTE: Brasília, v. 12, n. 22, pp. 163-172, 2018. 